\title{
Mechanisms of the Preventive Effect of Pilsicainide on Atrial Fibrillation Originating From the Pulmonary Vein
}

\author{
Masamichi Hirose, MD; Yosuke Ohkubo, BS; Michitoshi Takano, BS; \\ Mikihisa Hamazaki, BS; Takashi Sekido, BS; Mitsuhiko Yamada, MD
}

\begin{abstract}
Background It has been shown that pilsicainide terminates atrial fibrillation (AF) by pharmacologic pulmonary vein (PV) isolation. However, whether it can prevent AF induction originating from the PV by the same mechanism is still uncertain.

Methods and Results Rapid pacing from the left superior PV (LSPV) and the right atrial free wall (RAF) was performed to induce AF during electrical stimulation of both cervical vagal nerves in 6 anesthetized dogs and during the infusion of acetylcholine (ACh) in 8 isolated atria. Rapid pacing induced AF in all dogs, regardless of the pacing site, before pilsicainide. Pilsicainide $(1 \mathrm{mg} / \mathrm{kg})$ prevented AF during rapid pacing from the LSPV, with an impulse conduction block between the LSPV and the left atrial free wall (LAF). However, the same dose of pilsicainide did not prevent AF when pacing was performed from the RAF. Pilsicainide partially restored the action potential duration shortened by ACh infusion and prevented AF with an impulse conduction block at the LSPV-left atrial junction in all isolated preparations tested.

Conclusion The results suggest that (1) impulse conduction block at the LSPV-LA junction is the underlying mechanism of pilsicainide-induced prevention of vagally-induced AF originating from the LSPV and (2) pilsicainide is more effective at preventing AF originating from the LSPV than that from the RA. (Circ J 2007; 71: 1805-1814)
\end{abstract}

Key Words: Atrial fibrillation; Impulse conduction block; Pilsicainide; Pulmonary veins

C linical studies have shown that paroxysmal atrial fibrillation (AF) is initiated by focal discharges originating from the pulmonary veins (PVs) 1,2 This important finding has led to the development of several radiofrequency catheter ablation techniques to eliminate paroxysmal and persistent $\mathrm{AF}^{3-6}$ Recent studies have shown that complete isolation of the PV is important for preventing recurrence of $\mathrm{AF}^{7,8}$ In addition, Pappone et $\mathrm{al}^{9}$ have demonstrated that vagal denervation around the ostia of the $\mathrm{PVs}$ during catheter ablation reduces recurrence of $\mathrm{AF}$ originating from that site. Those studies emphasize the importance of complete isolation of the PVs, plush vagal denervation, in the prevention of AF originating from the PVs. Pilsicainide, a class Ic antiarrhythmic drug with slow recovery kinetics, ${ }^{10}$ is frequently used in clinical practice in Japan to interrupt AF!1,12 Several clinical and experimental studies have shown mechanisms of pilsicainide-induced termination of $A F 10,13-16$ but the mechanisms of pilsicainideinduced prevention of AF originating from the PVs are still unclear. It has been reported that pilsicainide inhibits the muscarinic acetylcholine receptor-operated potassium current $(\mathrm{IK}, \mathrm{ACh}) !^{17} \mathrm{In}$ addition, the IC 50 of pilsicainide for IK, $\mathrm{ACh}$ is similar to that for the sodium current ${ }^{17,18}$ We hypothesized that pilsicainide prevents AF originating from the

(Received April 3, 2007; revised manuscript received June 26, 2007; accepted July 10, 2007)

Department of Molecular Pharmacology, Shinshu University School of Medicine, Matsumoto, Japan

Mailing address: Masamichi Hirose, MD, Department of Molecular Pharmacology, Shinshu University School of Medicine, Matsumoto 390-8621, Japan. E-mail: hirose@ @sch.md.shinshu-u.ac.jp left superior PV (LSPV) by isolating the PV and reducing IK,ACh. First, the present study was designed to test whether pilsicainide could prevent AF originating from the LSPV during electrical stimulation of both cervical vagal nerves in anesthetized dogs. Then, to examine the mechanisms of pilsicainide-induced prevention of AF originating from the LSPV, a second study was performed using optical mapping techniques and pilsicainide treatment with constant acetylcholine (ACh) administration in isolated, arterially perfused, whole canine atria.

\section{Methods}

The experimental protocol was approved by the institutional animal experiments committee and complied with the Guide for Care and Use of Laboratory Animals published by the US National Institutes of Health (NIH publication 85-23, revised 1996).

\section{Anesthetized Dogs}

Six male dogs (weight $10-12 \mathrm{~kg}$ ) were anesthetized with sodium pentobarbital ( $30 \mathrm{mg} / \mathrm{kg}$ iv) with supplemental doses to maintain stable anesthesia. A tracheal cannula was inserted and intermittent positive-pressure ventilation with room air was delivered by a respirator (model 607, Harvard Apparatus, Millis, MA, USA). The chest was opened transversely at the fifth intercostal space and a pericardial cradle was created. The bilateral cervical vagal nerves were isolated via a midline neck incision and crushed with a tight ligature. Each stellate ganglion was isolated and crushed at its junction with the ansae subclaviae. These maneuvers 
remove almost all tonic neural activity to the heart. ${ }^{19}$

Three bipolar electrodes were placed on the epicardial surface of the left atrial free wall (LAF), the left inferior PV (LIPV) and the proximal site of LSPV (the site near the left atrial (LA)) to record atrial electrical activation. Electrocardiogram (ECG) lead II was also recorded and each of the 4 electrographic signals was filtered $(0.1-300 \mathrm{~Hz})$, digitized with 12-bit precision at a sampling rate of $1,000 \mathrm{~Hz}$ per channel (Microstar Laboratories Inc, Bellevue, WA, USA), transmitted to a microcomputer and saved to CD-ROM. To perform atrial pacing, an additional 2 bipolar electrodes were placed on the epicardial surface of the right atrial free wall (RAF) and the distal site of the LSPV (the site near the lung). To stimulate extracardiac parasympathetic nerves to the heart, bipolar stainless steel wire electrodes were inserted in the cardiac end of each cervical vagal nerve, and connected to an electrical stimulator (SEN 7103, Nihon Kohden, Tokyo, Japan). A catheter introducer was inserted into the left femoral artery to monitor arterial blood pressure. ECG lead II, heart rate, and femoral arterial blood pressure were monitored throughout the experiment.

\section{Isolated Canine Atria}

Eight male dogs (weighing 17-20 kg each) were treated with sodium heparin (500 USP units/kg iv) and anesthetized with sodium pentobarbital $(30 \mathrm{mg} / \mathrm{kg}$ iv). After a right thoracotomy, the heart and surrounding lungs were quickly removed and placed in cold cardioplegic solution of the following composition (mmol/L): $\mathrm{NaCl}, 130 ; \mathrm{KCl}, 8.0 ; \mathrm{CaCl}_{2}$, 1.8; $\mathrm{NaHCO}_{3}, 20.0 ; \mathrm{MgSO}_{4}, 1.0$ and dextrose, 5.5. Next, the entire atrium was isolated from the heart, the right and left coronary arteries were cannulated and leaking arteries were ligated. Two or more centimeters of each PV were retained intact with the rest of the LA. The preparation was mounted on a customized frame. A monophasic action potential electrode was placed on the epicardial surface of the posterior LA (PLA) and used to measure the action potential duration (APD). Each preparation was perfused under constant flow conditions with an oxygenated (95\% oxygen, $5 \% \mathrm{CO}_{2}$ ) Tyrode solution containing in mmol/L: $\mathrm{NaCl}, 130 ; \mathrm{KCl}, 4.0 ; \mathrm{CaCl}_{2}, 1.8 ; \mathrm{NaHCO}_{3}, 20.0 ; \mathrm{MgSO}_{4}$, 1.0 and dextrose, 5.5 ( $\mathrm{pH}$ of 7.4 at $36 \pm 1^{\circ} \mathrm{C}$ ). To avoid surface cooling, the preparation was immersed in the coronary effluent, which was maintained at a constant temperature (equal to the perfusion temperature) with a heat exchanger. Perfusion pressure was measured with a pressure transducer (Nihon Kohden Co, Tokyo, Japan) and maintained within range $(50-60 \mathrm{mmHg})$ by adjusting flow. Preparations were stained with $200 \mathrm{ml}$ of the voltage sensitive dye, di-4ANEPPS (Molecular Probes, Eugene, OR, USA) dissolved in $0.18 \mathrm{ml}$ of ethanol at a final concentration of $7.5 \mu \mathrm{mol} / \mathrm{L}$ by direct coronary perfusion for 7-10 min. Atrial rhythm was monitored using 3 silver disk electrodes fixed to the chamber in positions corresponding to ECG limb leads I, II, and III. The ECG signals were filtered $(0.3-300 \mathrm{~Hz})$, amplified $(\times 1,000)$, and displayed on a digital recorder. Preparations were maintained for $2 \mathrm{~h}$ without signs of deterioration, and our experimental protocol typically lasted $1-1.5 \mathrm{~h}$. After each experiment, tissue viability was confirmed by staining with $10 \mathrm{ml}$ of 2,3,5-tetrazolium chloride (14 mg/ml).

\section{Optical Mapping System}

Perfused whole atria were immersed in a Tyrode filled customized Lexan chamber specifically designed for optical recordings. The endocardial surface of the PVs was exposed to the optical mapping camera by inverting the vein insideout to visualize it from the ostium to the transition between myocardial and venous tissue. Gentle pressure was applied with a movable piston to the surface of the atria opposite to the mapping field, allowing the preparation to contract freely except within the mapping field. Electromechanical uncouplers were not used to reduce motion artifact. The optical mapping system used in this study has been described in detail previously. ${ }^{20}$ Briefly, excitation light $(500 \mathrm{~nm})$ obtained from a $250 \mathrm{~W}$ quartz tungsten halogen lamp (Oriel Co, Stratford, CT, USA) was directed at the heart using a liquid light guide. Light that was fluoresced from the heart was collected by a tandem lens assembly and directed to a long pass filter $(>610 \mathrm{~nm})$ that passes light of longer wavelengths to a $16 \times 16$ element photodiode array. The spatiotemporal resolution was 256,000 pixels/s. Signals recorded from each photodiode and the ECG signals were multiplexed and digitized with 12-bit precision at a sampling rate of $1,000 \mathrm{~Hz}$ per channel (Microstar Laboratories Inc, Bellevue, WA, USA). An optical magnification of $\times 0.81$ was used, corresponding to a mapping field of $2.1 \times 2.1 \mathrm{~cm}$ and $0.13 \mathrm{~cm}$ spatial resolution between recording pixels. To view, digitize, and store the anatomical features, a mirror was temporarily inserted between the lenses of the tandem lens assembly to direct reflected light to a digital video camera (DCR-PC120 Sony Co, Tokyo, Japan).

\section{Experimental Protocol}

Experiments using anesthetized canine hearts were performed $30 \mathrm{~min}$ after completion of the surgical procedures. To examine the effects of pilsicainide on the initiation of $\mathrm{AF}$, rapid pacing at a pacing cycle length (PCL) of 150 and $100 \mathrm{~ms}$ was performed from the distal LSPV or the RAF during cervical vagal stimulation before and after treatment with pilsicainide $(1-3 \mathrm{mg} / \mathrm{kg})$ in 6 autonomically decentralized hearts of the open-chest, anesthetized dogs. In this study, the right and left cervical vagal nerves were stimulated with a voltage of $10 \mathrm{~V}$, pulse duration of $0.03 \mathrm{~ms}$, and frequency of $3-10 \mathrm{~Hz}$. The stimulation intensity was adjusted to decrease the atrial rate by approximately 50-60\% before each experiment started and the intensity was unchanged throughout the experiment. Pilsicainide was injected from the right femoral vein over $20 \mathrm{~s}$. The protocol was started $2 \mathrm{~min}$ after the injection and ended in $15 \mathrm{~min}$ at each dose of pilsicainide. In half of the experiments, the LSPV pacing was first performed and then the RAF pacing. In the other half, the RAF pacing was first performed. Atrial electrical activations from 3 atrial sites (LAF, proximal LSPV, and LIPV) were obtained during each cycle length (CL) of rapid pacing and during the initiation of AF. In addition, to examine the effects of pilsicainide on atrial impulse conduction, conduction time from the LSPV to the LAF and from the RAF to the LAF was measured during LSPV and RAF pacing at a CL of $250 \mathrm{~ms}$, in the absence and during the vagal stimulation, respectively.

In the isolated arterially-perfused atrial preparations, a polytetrafluoroethylene-coated silver bipolar electrode with 1 -mm interelectrode spacing was used to stimulate the endocardial surface of the LSPV at 4-fold the diastolic threshold current with a duration of $1 \mathrm{~ms}$. Spontaneous activity was observed throughout the experiment. To examine the mechanisms of pilsicainide-induced prevention of cholinergically-induced AF originating from the LSPV, rapid pacing at a PCL of 400, 300, 200, 150, and $100 \mathrm{~ms}$ was performed 


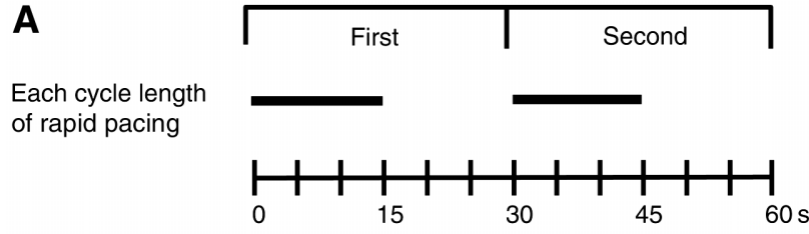

B

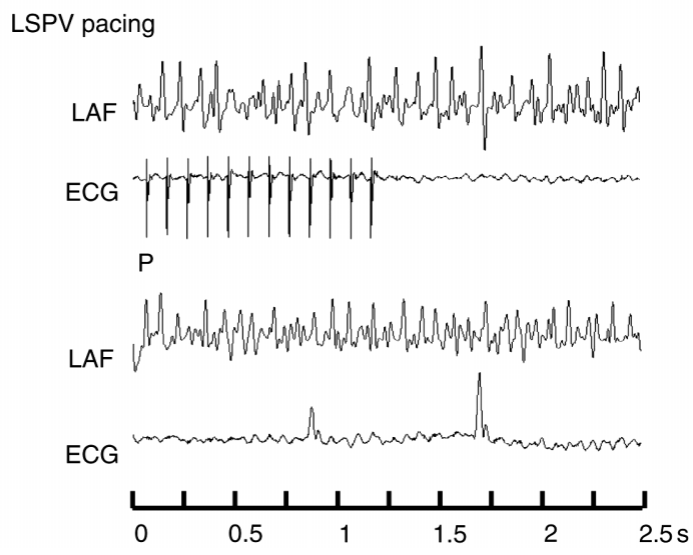

Fig 1. (A) Schematic diagram of the experimental protocol. Each cycle length of rapid pacing $(400,300,200,150$, and $100 \mathrm{~ms})$ was performed in anesthetized canine hearts and isolated arteriallyperfused atrial preparations. See text for details. (B) Example of atrial fibrillation induced following rapid pacing at a pacing cycle length of $100 \mathrm{~ms}$ during electrical stimulation of both cervical vagal nerves in anesthetized canine hearts. Rapid pacing was performed from the left superior pulmonary vein (LSPV) for $10 \mathrm{~s}$. An atrial electrogram was recorded from the left atrial free wall (LAF). ECG, electrocardiogram lead II; P, pacing artifact. See text for details.

from the LSPV during the infusion of ACh before and after treatment with pilsicainide ( 3 and $10 \mu \mathrm{mol} / \mathrm{L}$ ) in isolated atria. Each dose of pilsicainide was continuously infused from the right and left coronary artery and rapid pacing was started 2 min after the infusion started. Optical action potentials were obtained during each $\mathrm{CL}$ of rapid pacing and during the initiation of $\mathrm{AF}$.

In all experiments, the first rapid pacing at a given $\mathrm{CL}$ was performed for $10-15 \mathrm{~s}$, followed by spontaneous activity, and the second rapid pacing at the same CL was then performed for 10-15s (Fig 1A). AF initiation was defined as rapid ( $\mathrm{CL}<180 \mathrm{~ms}$ ) regular or irregular atrial rhythm persisting more than 10 beats after atrial pacing ended. When AF continued longer than $3 \mathrm{~min}$, vagal stimulation or $\mathrm{ACh}$ infusion was stopped. All AF terminated within 1 min after vagal stimulation or ACh infusion was stopped. Recovery time between experiments was appropriate to allow for the effects of the previous interventions to resolve.

\section{Data Analysis}

In experiments using isolated atria, automated algorithms were used to determine depolarization time relative to a single fiducial point (ie, the stimulus). Depolarization time was defined as the point of maximum positive derivative in the action potential upstroke $(\mathrm{dV} / \mathrm{dt} \max )$. Depolarization contour maps were computed for the entire mapping field. Repolarization time was defined as the time when repolarization reached a level of $80 \%$. The APD was defined as the difference between repolarization time and depolarization time. Local optical APD at the LSPV, the LSPV-LA junction, and the PLA was calculated from the average of optical APDs at 10 sites from each of the 3 areas. The method
Table 1 Incidence of Atrial Fibrillation Induced by Rapid Pacing During Electrical Stimulation of Both Cervical VS in Anesthetized Canine Hearts

\begin{tabular}{lcl}
\hline \hline \multirow{2}{*}{ Intervention } & \multicolumn{2}{c}{ Pacing site } \\
\cline { 2 - 3 } & Distal LSPV & \multicolumn{1}{c}{$R A F$} \\
\hline$V S(3 \mathrm{~Hz})$ & $6 / 6$ & $6 / 6$ \\
$V S+$ pilsicainide $(1 \mathrm{mg} / \mathrm{kg})$ & $1 / 6^{*}$ & $5 / 6$ \\
$V S+$ pilsicainide $(3 \mathrm{mg} / \mathrm{kg})$ & $0 / 6^{* *}$ & $0 / 6^{* *}$ \\
\hline
\end{tabular}

$V S$, vagal nerve stimulation; LSPV, left superior pulmonary vein; $R A F$, right atrial free wall.

$*_{p}<0.05$, $*_{p} p<0.01$ vs values at the corresponding pacing site during vagal stimulation before pilsicainide treatment. Fisher's exact test was used for the statistical analysis.

of Bayly et al ${ }^{21}$ was modified for optically recorded action potential maps to accurately quantify the direction and magnitude of conduction velocity $(\mathrm{CV})$ and the repolarization gradient at each recording site. Local CV was calculated from the average of conduction velocities at 12 sites from the LSPV-LA junction and from the PLA at each PCL. The local repolarization gradient was also calculated from the average of repolarization gradient at the same 12 sites from the LSPV-LA junction.

All data are shown as the mean \pm SE. An analysis of variance with Bonferroni's test was used for the statistical analysis of multiple comparisons of data. Student's t-test for paired or unpaired data was used for comparisons between 2 groups. Fisher's exact test was used to compare the incidence of AF between different conditions. $\mathrm{P}<0.05$ was considered statistically significant.

\section{Drugs}

Pilsicainide was provided by Daiichi Pharmaceutical Co (Tokyo, Japan) and was dissolved and diluted in $0.9 \%$ $\mathrm{NaCl}$. Acetylcholine chloride (Daiichi Pharmaceutical Co) was also dissolved and diluted in $0.9 \% \mathrm{NaCl}$. Kumagai et $\mathrm{al}^{13}$ have suggested that in patients with paroxysmal AF, the infusion of pilsicainide $(1 \mathrm{mg} / \mathrm{kg})$ may terminate $\mathrm{AF}$ by pharmacologic PV isolation. In addition, an effective plasma concentration of pilsicainide for treatment of arrhythmia is $2-10 \mu \mathrm{mol} / \mathrm{L} !^{18}$ Therefore, we used 1 and $3 \mathrm{mg} / \mathrm{kg}$ of pilsicainide in the anesthetized dogs and 3 and $10 \mu \mathrm{mol} / \mathrm{L}$ in the isolated preparations.

\section{Results}

Initiation and Duration of AF During Vagal Stimulation Before and After Pilsicainide Treatment in Anesthetized Dogs

The electrical stimulation of both cervical vagal nerves decreased the sinus rate from $104 \pm 3$ beats/min to $38 \pm$ 2 beats/min in 6 anesthetized canine hearts. After treatment with pilsicainide $(1 \mathrm{mg} / \mathrm{kg})$, vagal stimulation decreased the sinus rate to $42 \pm 3$ beats/min and the effect of vagal stimulation on the rate was similar to that before pilsicainide administration. In contrast, after treatment with pilsicainide $(3 \mathrm{mg} / \mathrm{kg})$, vagal stimulation decreased the sinus rate to $52 \pm$ 4 beats/min and the effect of vagal stimulation on the rate was inhibited compared with before pilsicainide $(p<0.01)$. Fig $1 \mathrm{~B}$ is a representative example of the initiation of AF by rapid atrial pacing during vagal stimulation. After $10 \mathrm{~s}$ of rapid pacing from the distal LSPV, an atrial electrogram recorded from the LAF showed rapid irregular excitation at a CL of less than $100 \mathrm{~ms}$. ECG lead II also demonstrated 
Distal LSPV pacing

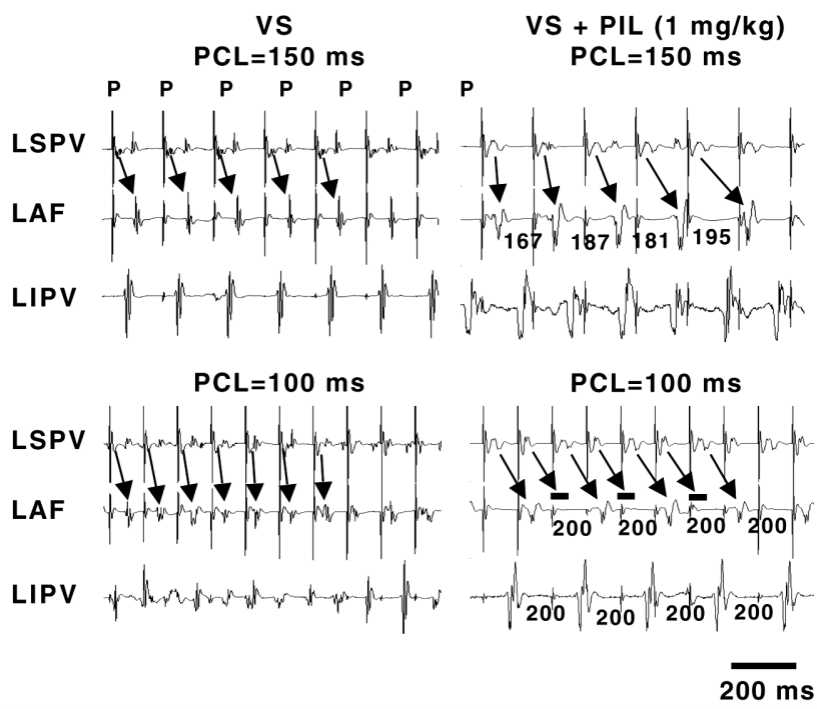

Fig 2. Representative example of atrial electrical activations recorded from the proximal left superior pulmonary vein (LSPV), left atrial free wall (LAF), and left inferior pulmonary vein (LIPV) during distal LSPV pacing before and after treatment with pilsicainide (PIL, $1.0 \mathrm{mg} / \mathrm{kg}$ ) in the presence of vagal stimulation. P, pacing artifact; PCL, pacing cycle length. See text for details.

\section{RAF pacing}

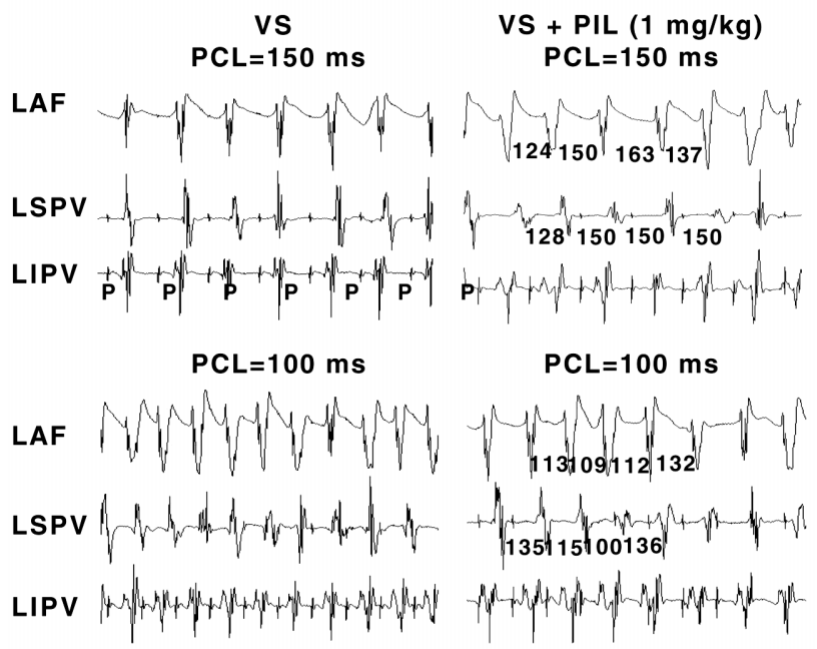

$200 \mathrm{~ms}$

Fig 3. Representative example of atrial electrical activations recorded from the proximal left superior pulmonary vein (LSPV), left atrial free wall (LAF), and left inferior pulmonary vein (LIPV) during right atrial free wall (RAF) pacing before and after treatment with pilsicainide (PIL, $1.0 \mathrm{mg} / \mathrm{kg}$ ) in the presence of vagal stimulation. P, pacing artifact; PCL, pacing cycle length. See text for details.

disorganized, almost continuous activity (ie, $\mathrm{f}$ wave) and irregular R-R intervals, which are ECG features of AF. During vagal stimulation, rapid pacing at a PCL of 150 and/or $100 \mathrm{~ms}$ initiated $\mathrm{AF}$ and continued it for more than $3 \mathrm{~min}$ in all 6 canine hearts, regardless of the pacing site (Table 1). After treatment with pilsicainide $(1 \mathrm{mg} / \mathrm{kg})$, rapid pacing from the LSPV initiated AF in only 1 heart during vagal stimulation (Table 1). However, rapid pacing from the RAF initiated $\mathrm{AF}$ and continued it for longer than $15 \mathrm{~s}$ in 5 hearts.

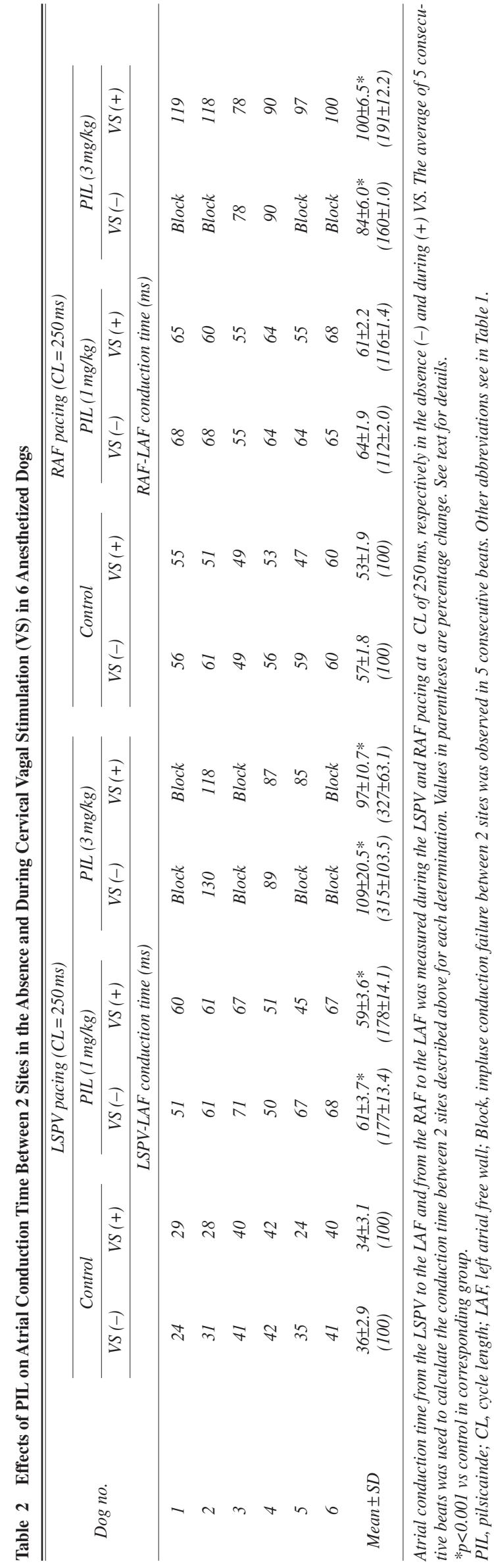

Circulation Journal Vol.71, November 2007 
A $\operatorname{APD} \operatorname{map}(\mathrm{CL}=400 \mathrm{~ms})$

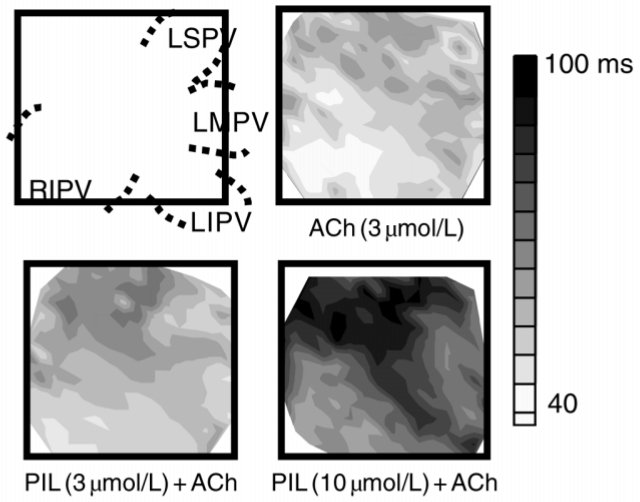

B

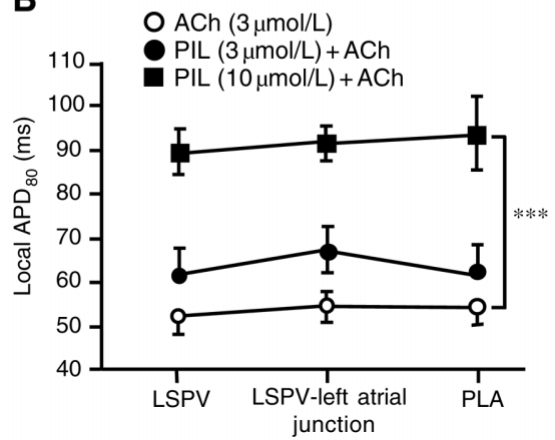

Fig 4. Action potential properties recorded during infusion of acetylcholine (ACh, $3 \mu \mathrm{mol} / \mathrm{L}$ ) before and after treatment with pilsicainide (PIL, 3 and $10 \mathrm{~mol} / \mathrm{L}$ ) at a pacing cycle length of $400 \mathrm{~ms}$. (A) Diagram showing mapping locations on the endocardial surface of the posterior left atrium (PLA), including PVs, and optical action potential duration (APD) maps. These maps reveal the spatial response of the optical APD to the infusion of ACh before and after treatment with pilsicainide. Shown to the right of the optical APD maps is a gray scale with corresponding numerical values. (B) Local optical APD at each of the left superior pulmonary vein (LSPV), the LSPV-left atrial junction, and the PLA in 8 preparations. Pilsicainide homogenously prolonged the local optical APD in 3 areas during ACh infusion. (C) Monophasic APD (MAPD) calculated from the MAP from the epicardial surface of the PLA in 6 isolated atria. $* * * \mathrm{p}<0.001$ vs values before pilsicainide infusion; ${ }^{+++} \mathrm{p}<0.001$ vs value before $\mathrm{ACh}$ infusion. LMPV, left middle pulmonary vein; RIPV, right inferior pulmonary vein.
After treatment with pilsicainide $(3 \mathrm{mg} / \mathrm{kg})$, rapid pacing did not initiate $\mathrm{AF}$, regardless of the pacing site and $\mathrm{CL}$ during vagal stimulation.

In the absence of vagal stimulation, rapid pacing from the LSPV initiated and terminated AF in $10 \mathrm{~s}$ in 2 canine hearts before treatment with pilsicainide.

\section{Preventive Effect of Pilsicainide on AF During Vagal Stimulation in Anesthetized Dogs}

Figs 2 and 3 are representative examples of atrial electrical activation recorded from 3 sites (proximal LSPV, LAF and LIPV) during distal LSPV or RAF pacing, respectively. Before pilsicainide was administered, when rapid pacing was performed from the LSPV at CLs of 150 and $100 \mathrm{~ms}$ during vagal stimulation, the 3 sites were excited at almost the same CL as the PCL (Fig 2, Left). In contrast, when rapid pacing was performed at a PCL of $150 \mathrm{~ms}$ during vagal stimulation after treatment with pilsicainide $(1 \mathrm{mg} / \mathrm{kg})$, the LAF was excited at a longer CL than the PCL and a Wenckebach type of conduction between the LSPV and the LAF was observed (Fig 3, Right). In addition, when rapid pacing was performed at a PCL of $100 \mathrm{~ms}$ during vagal stimulation, the LAF and LIPV were excited at a 2-fold longer CL than the PCL and a 2:1 conduction block between the LSPV and the LAF was observed (Fig 2, Right). In this preparation, rapid pacing induced AF before, but not after, treatment with pilsicainide (not shown). After treatment with pilsicainide $(1 \mathrm{mg} / \mathrm{kg})$, a similar pattern of atrial activation was observed in 5 canine hearts in which AF was not induced during LSPV pacing. When rapid pacing was performed from the RAF during vagal stimulation, atrial electrograms from 3 sites showed beat-by-beat changes in excitation CL after pilsicainide treatment $(1 \mathrm{mg} / \mathrm{kg})$ and $\mathrm{AF}$ was initiated (Fig 3, Right). No conduction block between the LSPV and the LAF was observed during RAF pacing.
After treatment with $3 \mathrm{mg} / \mathrm{kg}$ of pilsicainide, rapid pacing from the RAF at a PCL of $100 \mathrm{~ms}$ caused atrial electrical excitation at a longer CL than the PCL at all 3 sites and did not induce AF in any preparation.

\section{Effects of Pilsicainide on Impulse Conduction Time in Anesthetized Canine Atria}

Pilsicainide at a dose of $1 \mathrm{mg} / \mathrm{kg}$ significantly increased mean impulse conduction time from the LSPV to the LAF, both in the absence and during vagal stimulation in 6 anesthetized canine atria (Table2). However, the same dose of pilsicainide tended to increase the mean conduction time from the RAF to the LAF during RAF pacing, both in the absence and during the vagal stimulation, but it was not significant, indicating spatial differences in the effect of pilsicainide on impulse conduction in the atria. Moreover, the same dose of pilsicainide had little effect on atrial conduction time from the LSPV to the LAF in dog No. 4 in which the LSPV pacing induced AF during vagal stimulation after treatment with pilsicainide (Table 2). In contrast, $3 \mathrm{mg} / \mathrm{kg}$ of pilsicainide significantly increased mean conduction time regardless of the pacing site. These results suggest differences in the threshold dose of pilsicainide causing impulse conduction slowing between the atrium and PV.

\section{Initiation of AF During ACh Infusion Before and After Pilsicainide Treatment in Isolated Canine Atria}

During the LSPV pacing at a PCL of $100 \mathrm{~ms}$, AF was initiated and continued for longer than $3 \mathrm{~min}$ in all 8 preparations. After treatment with pilsicainide ( $3 \mu \mathrm{mol} / \mathrm{L})$, AF was also initiated in all of 6 preparations tested, but continued longer than $3 \mathrm{~min}$ in 1 preparation. In contrast, after treatment with pilsicainide at a dose of $10 \mu \mathrm{mol} / \mathrm{L}, \mathrm{AF}$ was not initiated in any of 6 preparations tested. In the absence of 


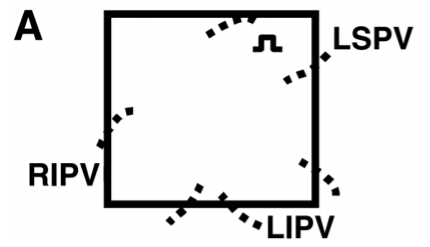

B
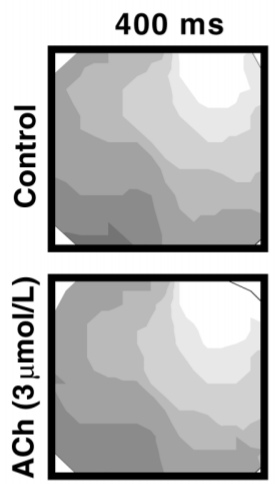

C

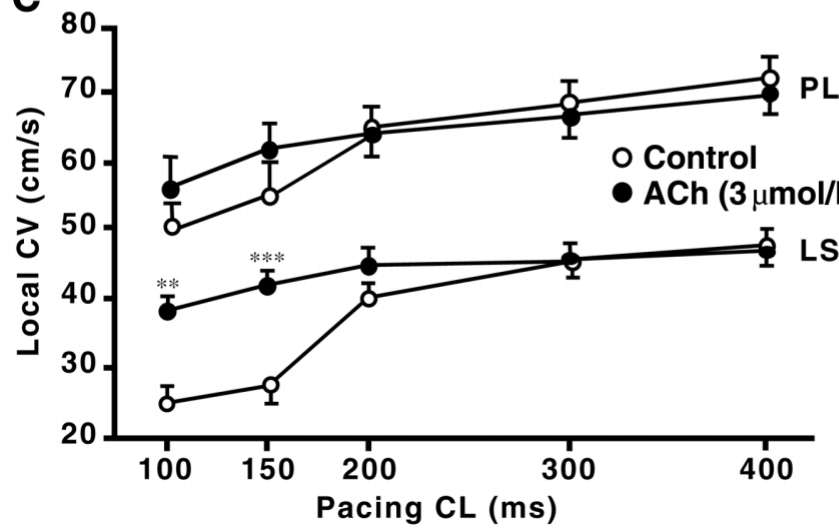

$200 \mathrm{~ms}$
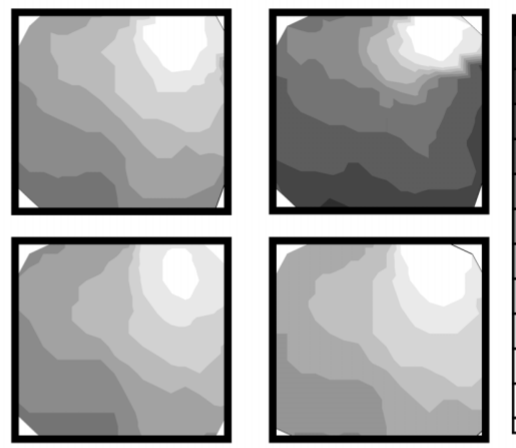

$55 \mathrm{~ms}$

25

。
Fig 5. (A,B) Diagram showing mapping location on the endocardial surface of the posterior left atrium (PLA), including pulmonary veins (PVs), and activation maps in the absence and during acetylcholine (Ach) infusion at pacing cycle lengths (PCLs) of 400, 200 and $150 \mathrm{~ms}$. These maps reveal the spatial response of impulse propagation to control and ACh infusion conditions. Shown to the right of the activation maps is a gray scale with corresponding numerical values. Activation maps are shown with 5-ms isochrones. (C) Local conduction velocity (CV) at each of the PLA and the left superior PV (LSPV)-left atrial (LA) junction in the absence of and during ACh infusion in 8 preparations. ACh restored impulse conduction slowing at the LSPV-LA junction during control at a cycle length (CL) of 150 and $100 \mathrm{~ms}$. **p $<0.01$, *** $\mathrm{p}<$ 0.001 vs values at the corresponding PCL in Control. LIPV, left inferior PV; RIPV, right inferior PV.
ACh, rapid pacing at a PCL of $100 \mathrm{~ms}$ from the LSPV initiated and terminated $\mathrm{AF}$ in $5 \mathrm{~s}$ in 1 preparation before treatment with pilsicainide.

\section{Effect of Pilsicainide on APD and LA Conduction During \\ ACh Infusion in Isolated Canine Atria}

Fig 4 shows the effects of pilsicainide on atrial APD in the LA, including the LSPV, during ACh infusion. APD maps and local APD in each of the 3 areas revealed that pilsicainide homogenously prolonged the atrial optical APD in the LA, including the LSPV (Figs 4A,B). In addition, the local repolarization gradient at the LSPV-LA junction was less than $3 \mathrm{~ms} / \mathrm{mm}$ in all 8 preparations after pilsicainide treatment. As we could not obtain authoritative APD data from the optical signals in the control condition because of motion artifact, a monophasic action potential was recorded from the epicardial surface of the PLA during LSPV pacing at a PCL of $400 \mathrm{~ms}$ in 6 isolated atria (Fig 4C). In the absence of ACh, pilsicainide $(10 \mu \mathrm{mol} / \mathrm{L})$ did not change the monophasic APD. In contrast, the same concentration of pilsicainide significantly increased the monophasic APD in the presence of $\mathrm{ACh}$.

Fig 5 shows the effects of ACh on the LA CV. Activation maps in the control condition revealed marked conduction slowing at the LSPV-LA junction during LSPV pacing at a PCL of $150 \mathrm{~ms}$ (illustrated by relative crowing of isochrones) (Fig 5B). During ACh infusion, the conduction slowing at the LSPV-LA junction in the control condition was markedly restored (illustrated by less crowing of isochrones). In contrast to impulse conduction at the junction, the activation pattern was less changed at the PLA, regardless of the intervention. Fig $5 \mathrm{C}$ shows the local $\mathrm{CV}$ at the PLA and the LSPV-LA junction in the absence of and during $\mathrm{ACh}$ infusion in 8 preparations. ACh increased the local CV at the LSPV-LA junction, compared with the control, at PCLs of 150 and $100 \mathrm{~ms}$. In contrast, the local CV at the PLA was not significantly different between the 2 conditions, even if the PCL was short.

Fig 6 shows the local CV at each of the PLA and the LSPV-LA junction during ACh infusion before and after treatment with pilsicainide. During ACh infusion, activation maps after pilsicainide $(3 \mu \mathrm{mol} / \mathrm{L})$ caused homogeneous conduction slowing in the mapping field compared with that before it (Fig 6A). Activation maps after pilsicainide (10u mol/L) revealed marked conduction slowing and block at the LSPV-LA junction (Fig 6A). Pilsicainide dose-dependently decreased the local CV at the LSPV-LA junction and the PLA (Fig 6B). Because the impulse conduction block at the LSPV-LA junction occurred in the first 3-5 beats of LSPV pacing at shorter CLs $(150$ and $100 \mathrm{~ms})$ after treatment with pilsicainide $(10 \mu \mathrm{mol} / \mathrm{L})$, we did not measure the local CV at the PCLs. 
A

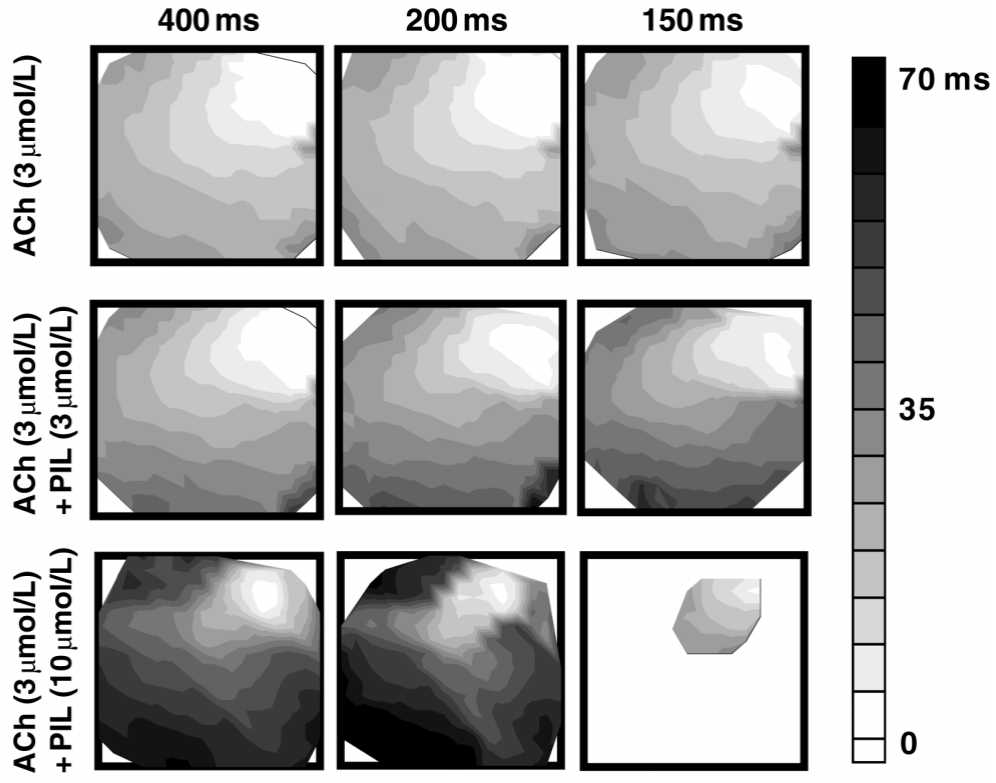

B

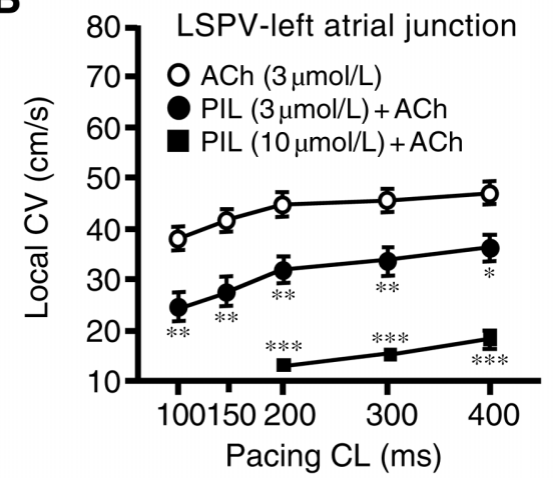

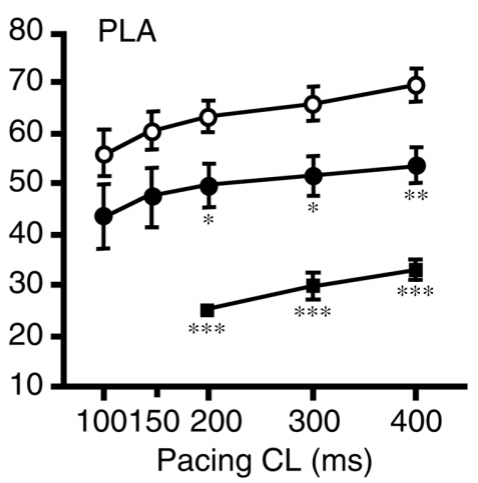

Fig 6. (A) Activation maps during acetylcholine (Ach) infusion before and after treatment with pilsicainide (PIL) at pacing cycle lengths (PCLs) of 400, 200 and $150 \mathrm{~ms}$. These maps reveal the spatial response of impulse propagation during ACh infusion before and after treatment with PIL. Shown to the right of the activation maps is a gray scale with corresponding numerical values. Activation maps are shown with 5-ms isochrones. (B) Local conduction velocity (CV) at each of the LSPV-left atrial (LA) junction and the posterior LA (PLA) during infusion of ACh before and after treatment with PIL in 8 preparations. PIL dose-dependently decreased local CV at the LSPV-LA junction regardless of PCL. $* \mathrm{p}<0.05, * * \mathrm{p}<0.01, * * * \mathrm{p}<0.001$ vs values at the corresponding PCL during $\mathrm{ACh}$ infusion before PIL infusion. CL, cycle length.

\section{Mechanisms of AF Prevention by Pilsicainide (19u $\mathrm{mol} / \mathrm{L})$ During ACh Infusion in Isolated Canine Atria}

Fig 7 is an example of the prevention of AF by pilsicainide $(10 \mu \mathrm{mol} / \mathrm{L})$ during infusion of $\mathrm{ACh}(3 \mu \mathrm{mol} / \mathrm{L})$. During LSPV pacing at a PCL of $200 \mathrm{~ms}$, the amplitude of the optical action potential at the LSPV was less changed and atrial muscle in the LSPV was continuously activated (Fig 7B-a). In contrast, the amplitude of the action potential at the LSPV-LA junction markedly decreased after $5.5 \mathrm{~s}$ of rapid pacing. In addition, after $5.5 \mathrm{~s}$ of pacing, the optical signal at the PLA disappeared even if pacing continued (Fig 7B-c). Activation maps during the $3^{\text {rd }}$ and $5^{\text {th }}$ beat (shown in panel B) showed impulse conduction slowing and a block at the LSPV-LA junction, respectively (Figs 7C,D). Moreover, the map obtained from the photodiode array with action potentials obtained during the period marked on panel B revealed that atrial muscles in the LSPV were activated (Fig 7E), indicating that pilsicainide caused impulse conduction block at the junction. However, the activation map during the $14^{\text {th }}$ beat in panel B showed that the beat originating outside the mapping field entered at the lower left of the field and then propagated toward the upper right including the LSPV (Fig 7E), suggesting that pilsicainide cannot cause impulse conduction block when the impulse propagates from the PLA toward the PVs. The impulse conduction block at the junction was observed in all of 6 preparations tested.

\section{Discussion}

\section{Role of Autonomic Tone at the PV-LA Junction}

It is well known that autonomic tone has an important role in the induction of AF. Recent experimental studies have demonstrated the importance of autonomic tone at the PVs and PV-LA junction in the induction of AF originating from the PVs.22,23 In addition, Pappone et $\mathrm{al}^{9}$ have demonstrated that vagal denervation around the ostia of the PVs reduces the recurrence of AF originating from the PVs. Moreover, Tritto et $\mathrm{al}^{24}$ have shown that adenosine restores impulse propagation between the LA and PVs after apparently successful ostial catheter ablation of the PVs. In the present study, we demonstrated that ACh increased the $\mathrm{CV}$ at the LSPV-LA junction, but not in the PLA. In addition, pilsicainide induced conduction slowing and conduction block at the junction in the presence of ACh and prevented $\mathrm{AF}$ induction and its maintenance. These results suggest that increased autonomic tone at the PV-LA junction contributes to $\mathrm{AF}$ induction and its maintenance via facilitation of impulse propagation between the PVs and the LA.

\section{Mechanism of Pilsicainide-Induced AF Prevention}

Iwasa et al ${ }^{16}$ showed that pilsicainide was more effective at terminating vagally-induced AF than propafenone, despite propafenone having increased the wavelength more than pilsicainide, suggesting that suppression of impulse propa- 
A

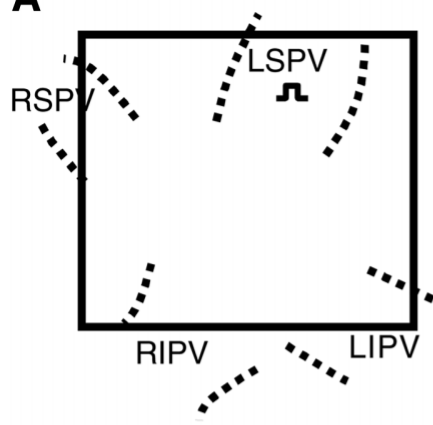

C

$(5210-5305)$

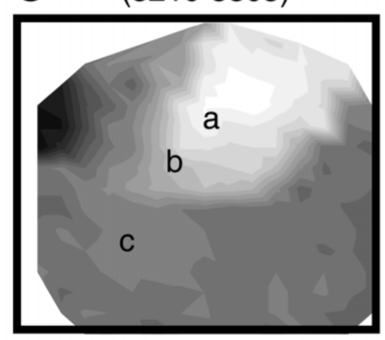

E

$(7440-7490)$

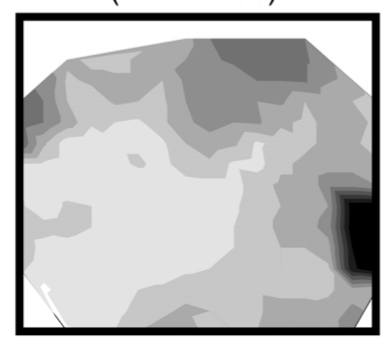

B

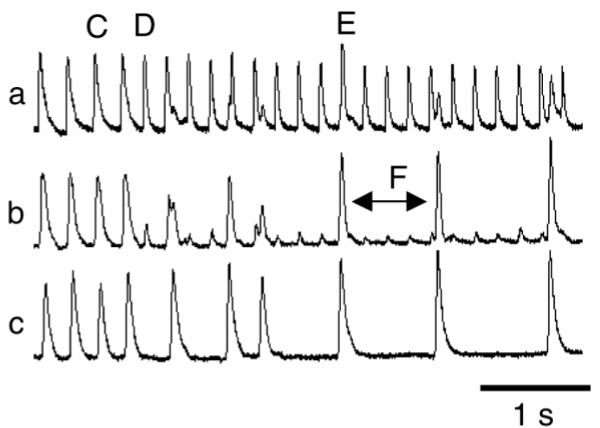

D

$(5620-5640)$

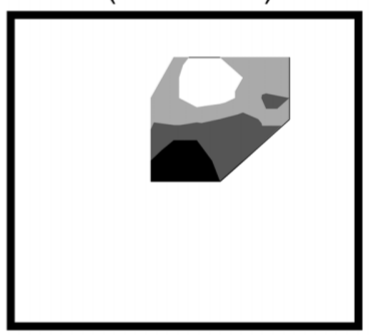

F Optical signals

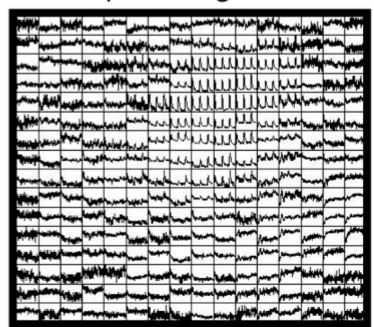

Fig 7. Example of the isolation of the pulmonary vein $(\mathrm{PV})$ with pilsicainide $(10 \mu \mathrm{mol} / \mathrm{L})$ during infusion of acetylcholine (Ach: $3 \mu \mathrm{mol} / \mathrm{L}$ ) at a pacing cycle length of $200 \mathrm{~ms}$. Pacing was performed from the distal left superior PV (LSPV). (A) Diagram of the mapping area (black box) showing relative location on the endocardial surface of the posterior left atrium (PLA) including PVs. (B) Optical action potentials recorded from the 3 sites marked on the activation map $(\mathrm{C})$ revealed that atrial muscle in the LSPV was continuously activated during pacing but the muscles in the LSPV-left atrial junction and the PLA were not. (C-E) Activation maps during the $3^{\text {rd }}, 5^{\text {th }}$, and $14^{\text {th }}$ beat in (B). (F) Map of a photodiode array with action potentials obtained from the endocardial surface of the PLA, including PVs, during the period marked on (B). Each square box represents a diode on the array and shows 3 consecutive action potentials drawn in its respective location. Activation maps are shown with 5-ms isochrones. Numerical data on the top of each activation map indicate the range of activation times within the mapping field. See text for details. RSPV, right superior PV; RIPV, right inferior PV; LIPV, left inferior PV. gation may be important for terminating $\mathrm{AF}$. In the present study, pilsicainide $(1 \mathrm{mg} / \mathrm{kg})$ significantly increased the conduction time between the LSPV and the LAF during LSPV pacing and prevented AF with a conduction block between the LSPV and the LAF during vagal stimulation in anesthetized canine atria (Table 2, Fig 2). In contrast, the same dose of pilsicainide tended to increase conduction time from the RAF to the LAF, but not significantly, and did not prevent AF during RAF pacing. Moreover, pilsicainide decreased the local CV at the LSPV-LA junction more effectively than at the PLA during infusion of ACh in isolated atrial preparations, and prevented $\mathrm{AF}$ with an impulse conduction block at the LSPV-LA junction. These results suggest that pilsicainide-induced suppression of the sodium current more effectively causes impulse conduction slowing and block in the atrial muscles of the LSPV-LA junction and prevents AF originating from the LSPV.

Several papers have reported that pilsicainide inhibits the IK, $\mathrm{ACh}_{17}^{17}$ the potassium channel current of human ethera-go-related gene $(H E R G)^{25}$ and the calcium current $(\mathrm{ICa})^{26}$ In addition, the IC50 of pilsicainide for IK,ACh was similar to that for sodium current ${ }^{17,18}$ In the present study, during vagal stimulation a higher, but not lower, dose of pilsicainide inhibited the effects of vagal stimulation on the sinus rate and prevented AF during RAF pacing in anesthetized canines. In addition, pilsicainide partially restored the left monophasic APD shortened by the infusion of $\mathrm{ACh}$ and prevented AF with an impulse conduction block at the LSPV-LA junction in isolated atrial preparations, suggesting that, in addition to inhibiting the sodium current, pilsicainide may cause partial inhibition of IK,ACh and prevent initiation of cholinergically-induced AF. In contrast, in the absence of $\mathrm{ACh}$, pilsicainide neither increased nor decreased the monophasic APD compared with the control, suggesting that it did not inhibit the ICa or the potassium current of HERG.

It is well recognized that impulse propagation is highly dependent on the structural arrangement of the tissue ${ }^{27,28}$ Recently, Hamabe et $\mathrm{al}^{29}$ have shown that tissue structure (segmental muscle disconnection and tissue expansion at the LSPV-LA junction) plays an important role in conduction disturbance at the LSPV-LA junction. Kumagai et al ${ }^{30}$ have shown that the effective refractory period of the PVLA junction is significantly longer than that of the distal PV. Laurita et $\mathrm{al}^{31}$ have shown that the formation of an unidirectional conduction block is critically dependent on the source-sink mismatch imposed by tissue structure and spatial heterogeneity of repolarization. In the present study, pilsicainide $(1 \mathrm{mg} / \mathrm{kg})$ caused impulse conduction block between the LSPV and the LA during LSPV pacing, but not during the RAF pacing, in anesthetized canines. In addition, pilsicainide homogeneously prolonged the optical APD in the LA and the LSPV during ACh infusion. Thus, these results suggest that the tissue structure of the junction plays an important role in pilsicainide-induced prevention of AF. Nevertheless, pilsicainide is a Class IC antiarrhythmic drug and has a sodium-channel blocking action with 
slow recovery kinetics and, therefore, it decreases tissue excitability and increases the refractoriness of atrial muscles. In addition, Yoshizawa et $\mathrm{al}^{32}$ have shown that a sodiumchannel blocker increases the total inexcitability of local tissue for activation conduction and then post-repolarization refractoriness, suggesting that pilsicainide would potentiate a source-sink mismatch. Thus, the increased source-sink mismatch at the junction in the presence of pilsicainide may result in a unidirectional conduction block, even if the repolarization gradient is small.

\section{Clinical Implications}

Recent studies have shown that complete isolation of the PV is important for preventing recurrence of paroxysmal AF. Ouyang et $\mathrm{al}^{33}$ have demonstrated that the recovery of conduction after complete circular isolation of the PV plays an important role in the recurrence of $\mathrm{AF}$ originating from the PVs. However, achieving complete isolation by ablation is technically challenging. We have demonstrated that pilsicainide in concentrations achievable in human plasma was more effective at preventing vagally-induced AF originating from the LSPV than from the right atrial (RA). Moreover, a clinical study has indicated that in the case of unsuccessful PV isolation by catheter ablation, pilsicainide may prevent AF by modifying the PV-LA conduction properties ${ }^{34}$ Therefore, pilsicainide may be a good drug for preventing the recurrence of $\mathrm{AF}$ originating from the $\mathrm{PVs}$ after catheter ablation.

\section{Conclusions}

We found that pilsicainide prevented vagally-induced AF originating from the LSPV with an impulse conduction block between the LSPV and the LA in anesthetized canines. In addition, a lower dose of pilsicainide prevented vagally-induced AF originating from the LSPV but not from the RA. Our study using isolated atrial preparations demonstrated that pilsicainide caused impulse conduction block at the LSPV-LA junction during LSPV pacing. These results suggest that (1) impulse conduction block at the LSPV-LA junction is an underlying mechanism in pilsicainideinduced prevention of AF originating from the LSPV and (2) pilsicainide is more effective at preventing AF originating from the LSPV than from the RA.

\section{References}

1. Chen SA, Hsieh MH, Tai CT, Tsai CF, Prakash VS, Yu WC, et al. Initiation of atrial fibrillation by ectopic beats originating from the pulmonary veins: Electrophysiological characteristics, pharmacological responses, and effects of radiofrequency ablation. Circulation 1999; 100: 1879-1886.

2. Haïssaguerre M, Jaïs P, Shah DC, Takahashi A, Hocini M, Quiniou G, et al. Spontaneous initiation of atrial fibrillation by ectopic beats originating in the pulmonary veins. N Engl J Med 1998; 339: 659-666.

3. Oral H, Knight BP, Tada H, Ozaydin M, Chugh A, Hassan S, et al. Pulmonary vein isolation for paroxysmal and persistent atrial fibrillation. Circulation 2002; 105: 1077-1081.

4. Takahashi A, Iesaka Y, Takahashi Y, Takahashi R, Kobayashi K, Takagi K, et al. Electrical connections between pulmonary veins: Implications for ostial ablation of pulmonary veins in patients with atrial fibrillation. Circulation 2002; 105: 2998-3003.

5. Pappone C, Oreto G, Rosanio S, Vicedomini G, Tocchi M, Gugliotta F, et al. Atrial electroanatomical remodeling after circumferential radiofrequency pulmonary vein isolation: Efficacy of an anatomic approach in a large cohort of patients with atrial fibrillation. Circulation 2001; 104: 2539-2544.

6. Oral H, Scharf C, Chugh A, Hall B, Cheung P, Good E, et al. Catheter ablation for paroxysmal atrial fibrillation segmental pulmonary vein ostial ablation versus left atrial ablation. Circulation 2003; 108: $2355-2360$.

7. Ernst S, Ouyang F, Lober F, Antz M, Kuck KH. Catheter-induced linear lesions in the left atrium in patients with atrial fibrillation: An electroanatomic study. J Am Coll Cardiol 2003; 42: 1271-1282.

8. Ouyang F, Bansch D, Ernst S, Schaumann A, Hachiya H, Chen M, et al. Complete isolation of left atrium surrounding the pulmonary veins: New insights from the double-Lasso technique in paroxysmal atrial fibrillation. Circulation 2004; 110: 2090-2096.

9. Pappone C, Santinelli V, Manguso F, Vicedomini G, Gugliotta F, Augello G, et al. Pulmonary vein denervation enhances long-term benefit after circumferential ablation for paroxysmal atrial fibrillation. Circulation 2004; 109: 327-334.

10. Sakai R, Inoue D, Ishibashi K, Inoue M, Shirayama T, Yamahara Y, et al. Kinetics of frequency-dependent conduction delay by class I antiarrhythmic drugs in human atrium. $J$ Cardiovasc Pharmacol 1995; 25: 953-960.

11. Atarashi H, Inoue H, Hiejima K, Hayakawa H. Conversion of recentonset atrial fibrillation by a single oral dose of pilsicainide (Pilsicainide Suppression Trial on atrial fibrillation): The PSTAF Investigators. Am J Cardiol 1996; 78: 694-697.

12. Kumagai K, Abe H, Hiraki T, Nakashima H, Oginosawa Y, Ikeda H, et al. Single oral administration of pilsicainide versus infusion of disopyramide for termination of paroxysmal atrial fibrillation: A multicenter trial. Pacing Clin Electrophysiol 2000; 23: 1880-1882.

13. Kumagai K, Tojo H, Noguchi H, Noguchi H, Yasuda T, Ogawa M, et al. Effects of the $\mathrm{Na}^{+}$channel blocker pilsicainide on the electrophysiologic properties of pulmonary veins in patients with atrial fibrillation. J Cardiovasc Electrophysiol 2004; 15: 1396-1401.

14. Shinagawa K, Mitamura H, Takeshita A, Sato T, Kanki H, Takatsuki $\mathrm{S}$, et al. Determination of refractory periods and conduction velocity during atrial fibrillation using atrial capture in dogs: Direct assessment of the wavelength and its modulation by a sodium channel blocker, pilsicainide. J Am Coll Cardiol 2000; 35: 246-253.

15. Kawase A, Ikeda T, Nakazawa K, Ashihara T, Namba T, Kubota T, et al. Widening of the excitable gap and enlargement of the core of reentry during atrial fibrillation with a pure sodium channel blocker in canine atria. Circulation 2003; 107: 905-910.

16. Iwasa A, Okumura K, Tabuchi T, Tsuchiya T, Tsunoda R, Matsunaga $\mathrm{T}$, et al. Effects of pilsicainide and propafenone on vagally induced atrial fibrillation: Role of suppressant effect in conductivity. Eur $J$ Pharmacol 1998; 356: 31-40.

17. Inomata $\mathrm{N}$, Ohno $\mathrm{T}$, Ishihara $\mathrm{T}$, Akaike $\mathrm{N}$. Antiarrhythmic agents act differently on the activation phase of the ACh-response in guinea-pig atrial myocytes. Br J Pharmacol 1993; 108: 111-115.

18. Kodama I, Ogawa S, Inoue H, Kasanuki H, Kato T, Mitamura H, et al. Profiles of aprindine, cibenzoline, pilsicainide and pirmenol in the framework of the Sicilian Gambit: The Guideline Committee for Clinical Use of Antiarrhythmic Drugs in Japan (Working Group of Arrhythmias of the Japanese Society of Electrocardiology). Jpn Circ $J$ 1999; 63: 1-12.

19. Levy ML, Ng ML, Zieske H. Functional distribution of the peripheral cardiac sympathetic pathway. Circ Res 1966; 19: 650-661.

20. Hirose M, Takeishi Y, Miyamoto T, Kubota I, Laurita KR, Chiba S. Mechanism for atrial tachyarrhythmia in chronic volume overloadinduced dilated atria. J Cardiovasc Electrophysiol 2005; 16: 1-10.

21. Bayly PV, KenKnight BH, Rogers JM, Hillsley RE, Ideker RE, Smith WM. Estimation of conduction velocity vector fields from epicardial mapping data. IEEE Trans Biomed Eng 1998; 45: 563-571.

22. Po SS, Scherlag BJ, Yamanashi WS, Edwards J, Zhou J, Wu R, et al. Experimental model for paroxysmal atrial fibrillation arising at the pulmonary vein-atrial junctions. Heart Rhythm 2006; 3: 201 -208.

23. Scherlag BJ, Yamanashi W, Patel U, Lazzara R, Jackman W. Autonomically induced conversion of pulmonary vein focal firing into atrial fibrillation. J Am Coll Cardiol 2005; 45: 1878-1886.

24. Tritto M, De Ponti R, Salerno-Uriarte JA, Spadacini G, Marazzi R, Moretti $\mathrm{P}$, et al. Adenosine restores atrio-venous conduction after apparently successful ostial isolation of the pulmonary veins. Eur Heart J 2004; 25: 2155-2163.

25. Wu LM, Orikabe M, Hirano Y, Kawano S, Hiraoka M. Effects of $\mathrm{Na}+$ channel blocker, pilsicainide, on HERG current expressed in HEK-293 cells. J Cardiovasc Pharmacol 2003; 42: 410-418.

26. Inomata N, Ishihara T, Akaike K. SUN1165: A new antiarrhythmic $\mathrm{Na}$ current blocker in ventricular myocytes of guinea-pig. Comp Biochem Physiol 1987; 87: 237-243.

27. Spach MS, Miller WT 3rd, Dolber PC, Kootsey JM, Sommer JR, Mosher CE Jr. The functional role of structural complexities in the propagation of depolarization in the atrium of the dog: Cardiac conduction disturbances due to discontinuities of effective axial resistivity. Circ Res 1982; 50: 175-191. 
28. Fast VG, Kleber AG. Cardiac tissue geometry as a determinant of unidirectional conduction block: Assessment of microscopic excitation spread by optical mapping in patterned cell cultures and in a computer model. Cardiovasc Res 1995; 29: 697-707.

29. Hamabe A, Okuyama Y, Miyauchi Y, Zhou S, Pak HN, Karagueuzian HS, et al. Correlation between anatomy and electrical activation in canine pulmonary veins. Circulation 2003; 107: 1550-1555.

30. Kumagai K, Ogawa M, Noguchi H, Yasuda T, Nakashima H, Saku K. Electrophysiologic properties of pulmonary vein assessed using a multielectrode basket catheter. J Am Coll Cardiol 2004; 43: 2281 2289.

31. Laurita KR, Rosenbaum DS. Interdependence of modulated dispersion and tissue structure in the mechanism of unidirectional block. Circ Res 2000; 87: 922-928.
32. Yoshizawa N, Niwano S, Moriguchi M, Kitano Y, Inuo K, Saito J, et al. Effect of procainamide on the postrepolarization refractoriness in cardiac muscle: Evaluation using the block coupling interval in the artificial isthmus model in the canine right atrium. Pacing Clin Electrophysiol 2001; 24: 1100-1107.

33. Ouyang F, Antz M, Ernst S, Hachiya H, Mavrakis H, Deger FT, et al. Recovered pulmonary vein conduction as a dominant factor for recurrent atrial tachyarrhythmias after complete circular isolation of the pulmonary veins: Lessons from double lasso technique Circulation 2005; 111: $127-135$.

34. Tojo H, Kumagai K, Noguchi H, Ogawa M, Yasuda T, Nakashima $\mathrm{H}$, et al. Hybrid therapy with pilsicainide and pulmonary vein isolation for atrial fibrillation. Circ J 2005; 69: 1503-1507. 